\title{
. Non-Volcanic Earthquake Swarm Near the - Harrat Lunayyir Volcanic Field, Saudi Arabia
}

\author{
M. Youssof, P. M. Mai, A. Nobile, and S. Jónsson \\ King Abdullah University of Science and Technology (KAUST), \\ Thuwal 23955-6900, Saudi Arabia
}

\begin{abstract}
Understanding the origin of seismic swarms can be controversial, especially when they occur near volcanic areas. Here, we investigate a seismic sequence which is steadily active in a non-volcanic area close by the volcanic field of Harrat Lunayyir in the western shield of Arabia.

Our results unveil a planar zone of seismicity with $\sim 5 \mathrm{~km}$ long E$\mathrm{W}$, sub-vertically $\sim 9 \mathrm{~km}$ south-dipping structure, which is characterized by a dominant tensional focal mechanism. Independent evidence for the tectonic style dominance came from assessing the ground deformation images using the InSAR technique. This local seismicity might be attributed to a reactivated structure along a regional weakness zone of the Najd Fault System, which dominates the Precambrian structure of our area.

Comparing the effects of high- and low-frequency datasets for the moment tensor inversion conclude a consistency of our solution. The frequency index analysis for $\mathrm{P}$ - and S- waves spectral datasets, does not suggest fluid-driven processes. We observe average stress drop of $\sim 5.40 \mathrm{MPa}$ with corner frequency of $\sim 2.75 \mathrm{~Hz}$.
\end{abstract}




\begin{abstract}
Our study confirms a localized reactivation of a brittle crustal seismogenic zone in the area of interest. This interpretation relies on the integration of several analysis methods, including spatial and magnitude-frequency distributions statistics.
\end{abstract}

Keywords - Non-volcanic swarm, full waveform moment tensor inversion, double-difference relocation, spectral index and stress drop analysis, flow-chart of data processing.

\title{
Plain Language Summary
}

In this study, we investigate a seismic sequence (started in February 2017), which is steadily active in a non-volcanic area close by $(\sim 50 \mathrm{~km} \mathrm{NW})$ the volcanic field of Harrat Lunayyir in the western shield of Arabia. We conclude that the occurrence of this earthquake swarm is not directly associated with a magmatic cause.

In this analysis, we implement various integrated approaches in a sequential workflow that provides a road-map for source parameter estimates. By applying these techniques, ruling out particular causes of seismicity gradually in a step by step process by a comprehensive, integrated data analysis approach is followed. This series of analyses determine whether the seismic sequences are caused by fluid-driven processes as they may occur in any area susceptible to volcano-earthquakes interactions. 


\section{${ }_{42} 1$ Introduction}

Earthquake swarms can be defined as sequences of events clustered in time and space, lacking a clear main shock (e.g. Hill 1977). They are different from the standard main-shock/aftershock scaling laws (Roland \& McGuire 2009). Swarms might be related to the occurrence and migration of fluids which may reduce normal stress along existent faults. In this case, physical processes modulate elastic strain energy released by such frequent events, which often characterized by a hypocentre migration in time and space (e.g. Waite \& Smith 2002; Hayashi \& Morita 2003; Hainzl 2004).

Swarm-like earthquakes are observed in a diverse range of geological settings including volcanic (Bianco et al. 2004; Guglielmino et al.2011, Passarelli et al. 2015, White \& McCausland 2019), geothermal regions (Dziak et al. 2003), along transform plate boundaries, as well as active rift zones (Baer et al. 2008; Pallister et al. 2010), where earthquake swarms are mainly associated with shallow extensional fractures (Pollard et al.1983; Rubin \& Pollard 1988, Vidale \& Shearer 2006).

Swarms' seismic signals can be related to both contributions of fluid- and tectonic-driven processes that may coexist in the same interactive system. Nevertheless, the manifestations of seismicity related to volcanic activity can be spatially and temporally ambiguous, especially when the sequences are close by volcanic areas (Legrand et al. 2002; Hill et al., 2002; Manga and Brodsky, 2006).

The seismotectonic Cenozoic activity in the Arabian Shield is considered to be, at least partially, associated with rifting of the Red Sea that has led to 
uplift and volcanism throughout the shield, resulting in extensive lava fields (called harrats, locally) that cover an area of $\sim 180,000 \mathrm{~km}^{2}$ (Coleman et al., 1983) (Figure 1 and supplementary Figure S1). Intraplate volcanism resulted in at least 21 eruptions in Arabia during the past 1500 years (Camp et al., 1987). Some of these eruptions fields display geothermal features such as elevated groundwater temperatures and fumarole emissions (Roobol et al., 1994). It has also been suggested that the entire area of harrats is underlain by asthenospheric flow channelized northward from Afar (Camp and Roobol, 1992; Hansen et al., 2006; Chang et al., 2011).

Earthquake swarms in Arabia are taking place at different locations where they are recorded by dense seismic arrays of $\sim 300$ stations (Soliman et al. 2019). The seismically active regions around the Red Sea flanks are generally similar in terms of formation age, and dominant geological settings. The main geological exception represents a prominent volcanism at the eastern margin of the Red Sea, in contrast to the western side in Egypt and Sudan where a few flood basaltic fields exist (Pallister 1987). Regardless, the origin of several seismic activities in this region are enigmatic. As shown in the supplementary material (Table S1 and supplementary Figure S1), we assembled some data about these swarms. Different studies suggests that some of them are triggered by magmatic processes underneath or close by the surface exposure of the harrats areas.

This western part of the Arabian Shield, where Harrat Lunayyir is located, comprises of amalgamated belts of sedimentary and metamorphic rock units that are penetrated by the regional Precambrian Najd Fault System and intervened by numerous dikes (e.g., Blasband et al. 2000; Johnson 2003). 
Harrat Lunayyir is a small volcanic field in the Arabian Shield, covering an area of $\sim 3500 \mathrm{~km}^{2}$, situated within the passive margin of the northern Red Sea region. This region contains large number of volcanic cones $(>50)$ that follow the NW-SE trending normal faults (Baer and Hamiel, 2010; Al-Amri et al., 2012, Jónsson, 2012, Trippanera et al. 2019).

Here, we mainly focus our investigation on a sequence of relatively smallmagnitude events located NW of Harrat Lunayyir, which started in February 2017 and it is still taking place with a daily rate. The Saudi Geological Survey (SGS) provided us with $\sim 10$ months waveform dataset of events started from February 8th, 2017 (characterized by a magnitude range of $M_{L}-0.75$ to 3.73), registered in this locality (Figure 1). This swarm attracted the interests of local authorities due to previous intense seismic activity in the vicinity in 2009, related to volcanic unrest at Harrat Lunayyir. The local network of SGS registered this unrest with more than 30k events between April to July 2009 with magnitudes ranged from $M_{L}-0.7$ to 5.4 (Baer and Hamiel, 2010). This activity also experienced a dike intrusion, including $\sim 8 \mathrm{~km}$ surface rupturing $M_{W} 5.7$ earthquake (Pallister et al. 2010). In the post diking phase, micro-seismicity has been continuously registered in the dike-induced graben up to present (Nobile et al. 2020).

In this study, we integrate several seismic analysis methods to mainly investigate the properties of the 2017 earthquake sequence. We inspect the spatiotemporal statistics from the catalog information by examining the magnitude-frequency distribution. We apply the double-difference earthquake relocation algorithm (Waldhauser et al. 2000) to relocate the swarm events. We constrain source depth and focal mechanism for selected events 
using full waveform moment tensor inversion constrained with a grid-search over source depth (Ichinose et al. 2003). Furthermore, we estimate static stress drop, corner frequency, and seismic moment from displacement amplitude spectra for the largest events. We then apply the frequency index method to characterize the spectra of the swarm signals (Buurman \& West 2010). Finally, to further constrain our results, we evaluated the ground deformations in the area through InSAR imaging. To compare the results of analyzing the 2017 swarm with some swarms around, we study two other seismic sequences which occurred in 2009 and 2018. For analyzing these two cases, we use only two methods because of data limitation. Our integrated data analyses lead us to conclude that the ongoing seismic sequence (started in 2017) is of a tectonic origin, and not directly linked to the nearby continuous activity of the volcanic field of Harrat Lunayyir.

\section{Earthquake Data : Statistics and Locations}

In the study area, we use seismic records from 44 stations operated by SGS.

The network geometry forms a polygonal area of $\sim 375 \times 200 \mathrm{~km}^{2}$ with a centeriod point of $25.5^{\circ}, 37.5^{\circ}$ bounded between Harrat Lunayyir to the south and the northern 2017 swarm location (Figure 1 and supplementary figures S1 and S2). Despite 33 existing stations in the area before this 2017 swarms begun, SGS densified the local network by adding 11 more permanent stations during the first three months of the swarm. All instruments are broadband three-component sensors with the ability to record static displacements down to the DC offsets and up to frequencies limited by the sampling rate of 100 
Hz. SGS provided the data in a compacted full-SEED format with a time duration of 565 s, for a period spanning from February 2017 to November 2017.

We filtered the seismic data between 1-25 s, depending on the study purposes and method. We categorize the high frequency range between 1-10 $\mathrm{s}$, and the low frequency range between 5-25 s. The advantages of using different frequency bands is multifold. For instance, the relatively long-period signals $(0.04 \mathrm{~Hz}-0.15 \mathrm{~Hz})$ improve the estimation of earthquake source parameters because they are relatively insensitive to the effects of lateral velocity and density heterogeneities (e.g., Ritsema and Lay, 1995, Ichinose et al. 2003). Using relatively short-period signals $(0.1 \mathrm{~Hz}-1.0 \mathrm{~Hz})$ help refining the sensitivity for structural details at a given depth and help verifying the velocity model used in the inversions.

The first-order approach to identify whether seismic events accommodated by some fault-like characters or not is to estimate the magnitudefrequency distribution (MFD) in addition to applying a relative relocation technique. The following two subsections will help shaping an initial rough understanding of the temporal and spatial evaluations of the 2017 seismic swarm, north of Harrat Lunayyir region.

\subsection{Magnitude Frequency Distribution}

Statistical properties of a given seismicity can be analyzed using MFD. This method describes the rate of events occurrences across all magnitudes. We determine the MFD following the Gutenberg-Richter relationship: $(\log \mathrm{N}=\mathrm{a}-\mathrm{bM})$, 
where $\mathrm{N}$ is a number of events having a magnitude $\geq M$, while $a$ and $b$ are constants. The $b$-value indicates the ratio of small to large events, the constant $a$ is the logarithm of the events number with $M \geq 0$, which quantifies the events productivity of a sequence. In this context, the magnitude of completeness $\left(M_{C}\right)$, represents the lowest magnitudes that is reliably recorded by the seismic network. We estimated the $M_{C}$ by the maximum curvature approach (Wiemer and Wyss, 2000; Woessner and Wiemer, 2005), which defines it by the largest value of the second derivative of the MFD curve.

For calculating the MFD, a complete catalog should be used containing magnitudes $M_{L} \geq M_{C}$, and $M_{L}$ ranges at least over 2.0 magnitudes. Note that only the MFDs derived from similar definition of local magnitude are comparable. The network-based standard magnitudes produced by SGS are based on two definitions for $M_{L}$ (Soliman et al. 2019), depending on the area distances and tectonics (supplementary material: Appendix (A)).

For a total number of 390 events for the 2017 swarm within the local area (NNW Harrat Lunayyir, Figure 1), we obtain a $b$-value of $0.73, M_{C}$ of 0.73 , and $\mathrm{a}=3.10$. For comparison, we also use a complete catalog $(\sim 15 \mathrm{k}$ events during 2015-2018) within the entire area of Lunayyir volcanic field. Calculating b, $M_{C}$, and a-values for the whole region (during these four years, excluding the events of 2017 swarm) results in $b$-value $=1.27, M_{C}=0.25$, and $a=4.02$ respectively (Figure 2 ). These results of the two $M_{C}$ values agree with Soliman et al. 2019.

Figure (2) shows the main difference between the background larger-scale seismicity and the local 2017 swarm. Figure 2a represents the seismicity peak during the 2017 unrest within the temporal and spatial boundaries 
of this seismic activity, while the cumulative seismic moment inset curve shows the jump in the moment release versus time for the 2017 and 2018 main events. Figure $2 \mathrm{~b}$ confirms the varying statistical relation between the MFD curves for the two different seismicity. This statistics result suggests an interpretation of the 2017 activity to be more of a tectonic origin than a magmatic one.

\subsection{Relative Relocation}

We compute relative earthquake locations using the double-difference technique (Waldhauser and Ellsworth, 2000), based on an enhanced HypoDD code that includes $3 \mathrm{D}$ ray tracing to calculate travel times within a volumetric velocity model. The standard process of this algorithm iteratively minimizes arrival time residuals using weighted least squares methods, with either a singular value decomposition (SVD) or a conjugate gradient (LSQR) approaches. SVD performs well for up to few hundreds of events to produce more accurate error estimates than the computationally efficient LSQR method (Waldhauser and Ellsworth, 2000). As background models, we use the P-wave velocity model of Tang et al. (2016) along with a calculated S-wave model (Figure 3) using a constant $\mathrm{V}_{P} / \mathrm{V}_{S}$ of 1.76 .

We apply this algorithm to obtain precise hypocenters of a total of 390 earthquakes, as reported in the SGS catalog for $\sim 10$ months in 2017. Earthquakes locations before and after applying the double-difference technique are shown in Figure 3 and supplementary Figure S3.

Relative relocations results show interesting space-time pattern for the 
events with larger magnitudes clustered in the swarm beginning (during the first few months), at the deepest level of $\sim 12 \mathrm{~km}$. Events with smaller magnitudes progressively migrated upward. Shallower events cluster between 5 to $8 \mathrm{~km}$ depth, forming an E-W narrow corridor of $5 \mathrm{Km}$ length (as shown in the surface projection in Figure 3 and supplementary Figure S3). The bulk spatial shift in the horizontal E-W plane between the initially located events by SGS and the new relocated events is $0.03^{\circ}$ while the difference in depths represents clustering the initially located scattered events into deeper depths for the new relocated ones (Figure 3). Overall, the original locations show a diffuse spatial pattern whereas the relocation solution represents a sense of fault-like structure.

The hypoDD errors depend on the array geometry, data quality, and maximum separation between any pair of events, where this offset has to be at least 10 times smaller than event-station distance. The available stations here are sparsely distributed (uneven but dense array, Figure 1) but of a good data quality (supplementary Figure S4). We obtain a total number of 21138 P-and S- wave deferential travel-times using the 44 stations around the events. The average offset between linked events is $2.2 \mathrm{~km}$, while the maximum offset is $14.8 \mathrm{~km}$. This offset ranges are within the average station separation of $\sim 40 \mathrm{~km}$ of the array, and events within the region are on average linked by at least 10 arrivals. We choose the SVD method as it produces reliable error estimates in this case of small dataset. Note that the doubledifference relocations have much smaller errors than the network locations. While the aim is to relocate the swarm by combining all the P-and S-wave available datasets, relocating events using each data type independently was 
useful to assess the solution consistency and quality of both datasets.

Utilizing this dense array and its high-quality data (Figures 1 and 4a, respectively), we apply a waveform-based sensitivity test for constraining the location uncertainty using the largest event of the 2017 swarm as a reference. Backprojecting the incident rays into the source via a beamforming technique amplifies phases with the appropriate slowness, while suppressing incoherent noise and phases with different slowness (supplementary material: Appendix (B)). The frequency-wave number analysis (fk-analysis) measures the complete slowness vector (i.e., back azimuth and horizontal slowness simultaneously), and allows to calculate the power distributed among different slownesses and directions of approach (Aki and Richards, 1980).

In the current case, for the coherent incident waves with a frequency of 1 $\mathrm{Hz}$, the maximum power spectral density (PSD) for a P-wave signal arrives with a slowness of $15.65 \mathrm{~s} / \mathrm{deg}$ and a back azimuth of $324^{\circ}$ (Figure $4 \mathrm{c}$ ). For comparison, we calculate the expected phase travel times and ray parameters given the coordinates of the stations and relocated source for the same event. The average theoretical ray parameters are 16.1 , and $28.7 \mathrm{~s} /{ }^{\circ}$ for $\mathrm{P}$ - and $\mathrm{S}$ wave, respectively (Table S2). These predicted values agree well with the fk-analysis, confirming the observed and relocated hypocenter of the event of interest.

\section{Earthquake Source Characteristic}

Full waveforms techniques for investigating focal mechanism and spectral content can help reflecting some features of the fault plane. For instance, 
seismic moment tensors provide a useful tool for distinguishing between tectonic earthquakes and events associated with volcanic processes (e.g. Dreger et al., 2000), as well as other man-made sources of seismic radiation such as explosions or mining activity (e.g. Ford et al., 2009). Additionally, analyzing the spectral content can identify the radiated seismic energy and hence predicts the stress-changes. In this section, we apply a couple of techniques utilizing full-waveform data of some selected events of interest (taken place in 2009,2017 , and 2018), to delineate the frequency contents and the focal mechanisms. Furthermore, we apply InSAR imaging to assess whether any discernible ground deformation was associated with the 2017 seismic swarm.

\subsection{Seismic Moment Tensor Inversion}

We use both first-motion fault mechanisms and full-waveform moment tensor inversion, following Ichinose et al. (2003). We compute Green's functions for $2 \mathrm{~km}$ depth increments, using a fast reflectivity and fk-summation (Zeng \& Anderson 1995). We then iteratively solve for the source depth using a grid search scheme.

The sensitivity of the moment tensor solutions was tested by using different local and regional velocity models as implemented in the relocation method, as well as by using different frequency bands in the inversions. Note that using long-period energy avoids the need for modeling complex crustal structure, while large epicentral distances allow for using simple 1D velocity models (Jost and Herrmann 1989).

The quality of waveform fits for different stations are shown in Figure 
5 (for the $M_{W} 3.6$ event of March 10, 2017) and in supplementary figures S5 and S6 (for some more selected stations recorded the same event). The mismatches in phase show an average variance reduction of $86 \%$ and $83 \%$ for the long- and short-period data, respectively, where the misfit in amplitude between observed and synthetic waveforms provides useful information about the accuracy of the available velocity model.

We compare both solutions of high- and low-frequency moment tensors. Both results (Figure 5) provide same fault-plane solution, indicating that the local velocity structure model used in the inversion is accurate to predict both high- and low-frequencies signals. Furthermore, this solution confirms the exact same geometrical trend of E-W fracture zone implied by the relative relocation analysis (Figure 3). The depth of the largest events are reasonably in agreement in both methods of double-difference and full-waveform moment tensor inversions. More details about the moment tensor inversion output is shown in Figure 5, which is also presented in the supplementary materials with all stations used in the inversion (supplementary figures S5 and S6).

The same inversion procedure is additionally applied to eight more events, ranging in magnitude from $M_{W} 2.8$ to 3.6 from the 2017 swarm. The results are summarized using the fundamental lune of Riedesel \& Jordan (1989) and Tape \& Tape (2018) (Figure 6a). This plot visualize the geometry of a point source moment-rate tensor estimates. It also demonstrates the decomposition of moment tensors into isotropic (ISO), double-couple (DC) and compensated linear vector dipole (CLVD) components. This result (Figure 6a) reveals that the majority of the events are double-couple components with a small CLVD contribution. 
As we acquired knowledge of which nodal plane is the main fault, a stress inversion from the focal mechanism can be conducted. Note that the main stress regime is a function of the orientation of the principal stress axes and the shape of the stress ellipsoid, meaning it results in extensional mechanism when $\sigma_{1}$ is vertical. We therefore compute the stress axes following Vavryčuk (2014) where the input data for the inversion are the strike, dip, and rake angles obtained from the moment tensor solutions. The stress tensor inversion results in a sub-vertical $\sigma_{1}$ axis and sub-horizontal $\sigma_{2}$ and $\sigma_{3}$ axes as in Figure 6b.

\subsection{Stress Drop and Spectral Index Analysis}

One of the important earthquake source parameters is stress drop $\Delta \sigma$, i.e., the difference between the average shear stress on the fault plane before and after an earthquake. The main consideration about this method is the results non-uniqueness because $\Delta \sigma$ uncertainty quantification is not often helping to interpret results with confidence (e.g., Abercrombie 2015). For instance, some stress-drop studies show higher stress drops for both normal (Shearer et al., 2006) and strike-slip events (Allmann and Shearer, 2009), whereas others report no dependence on focal mechanisms (e.g., Oth, 2013). Other studies suggest that stress drop depends on tectonic setting, depth, or both (e.g., Boyd et al., 2017).

In this work, using the source model of Brune (1970) and Madariaga (1976), we estimate stress drop from the Fourier source spectra (computed for the displacement time-series), which include the corner frequency $f_{c}$ (e.g., 
Boatwright, 1984). We calculate $(\Delta \sigma)$ using the Eshelby (1957) relationship (supplementary material: Appendix (C)).

Figure 7 shows few findings of our spectral-fitting procedure for the largest earthquake at different stations. These examples represent results of the four main azimuths, which surround the $M_{L} 3.73$ earthquake. From this example, the best fitting theoretical model (dashed blue line) has corner frequencies between $2.14 \mathrm{~Hz}$ and $4.95 \mathrm{~Hz}$, with a stress drop of $4.56 \mathrm{MPa}$ and 11.32 MPa, respectively. Most values for the stress drop and seismic moment fall in the ranges $(0.95-17 \mathrm{MPa})$ and $\left(0.58 \times 10^{13}-1.74 \times 10^{14} \mathrm{Nm}\right)$, respectively (Figure 8). Additionally, we notice that some parts of the amplitude spectra can not be fitted using the predicted models. At low-frequency $(\leq 0.7 \mathrm{~Hz})$, the misfit might be attributed to the static and permanent displacements where the background seismicity can be a reason for such low-frequency noises. While at the other end of the spectrum, a high-frequency range $(\geq 35 \mathrm{~Hz})$ contaminates the signal with less contribution than the low frequency (Figure 7)

Furthermore, our estimates of $\Delta \sigma, f_{c}$, and $M_{0}$ indicate azimuthal variations around event hypocenters. The azimuthal variations for the median $\Delta \sigma$ range from 4.7 to $6.9 \mathrm{MPa}$ over different epicentral distances (Table S3). This variation needs further investigation, which is out of this paper's scope, but this directional variability is probably due to directivity effects. Our results also indicate that the individual event stress drops are heterogeneous and span from 0.95 to over $17 \mathrm{MPa}$ (for the largest three events, as shown in Figure 8). Note that the upper limit is not reliably well-determined because resolution decreases for corner frequencies. Therefore, we estimate the $\Delta \sigma$ 
uncertainty using the spectra of $\mathrm{P}$ - and S-waves for a comparison calculations of $f_{c}$ and $M_{0}$. The results are shown in Figure 8.

Another method to discriminate between different source processes can be deduced from the ratio between separated frequency bands within a given seismic signal. The dominant frequency, can be also used as a general proxy for spectral content and to characterize waveform types (e.g. Latter, 1980; McNutt, 2002). However, shortcomings arise when using it as a measure of the overall frequency content, for instance, in case of low signal-to-noise ratio (SNR) recordings or for events with bimodal frequency distributions, because the dominant frequency measures only the highest peak in the spectra and therefore grouping it with other single-peaked events (a particular issue for hybrid-type earthquakes).

These limitations associated with dominant frequency led Buurman and West (2010) to develop a measure to discriminate between different types of seismic events, defines the frequency index $(F I)$ based on the ratio of energy in low and high frequency windows (supplementary material: Appendix (D)). For instance, waveforms with equal amounts of high and low energy (as subjectively defined) will have a frequency index around zero. Whereas, a smaller FI than this average means the waveform is dominated by lowfrequency energy, while otherwise FI demonstrates a majority of energy in the high-frequency band.

To calculate the $F I$ in a consistent manner, we first pick the $\mathrm{P}$ - and S-onsets, minimizing the time window to approximately the P-S duration, followed by removing the average amplitude from the selected waveforms signals, with a fixed time series duration of 40 seconds: 10 seconds prior 
to the earthquake $\mathrm{P}$-onset and 30 seconds after it, ensuring that the high frequency signal is fully captured in the Fourier analysis. Examples of the FI analysis for the largest events in the 2009, 2017, and 2018 sequences are shown in Figure 9 with the results values listed in Table S4. Here, this index classified the main event of 2017 as an exclusively high-frequency event, which is contrasted the other known magmatic case of 2009 in Harrat Lunayyir.

\subsection{Ground Deformation using InSAR}

As magma moves to shallower levels below the surface, it usually produces characteristic ground deformation, seismicity, and gas emissions (e.g., Dzurisin 2007; Biggs and Pritchard, 2017; Sigmundsson et al. 2018). During magmatic intrusions, the seismic moment could be a small fraction of the total geodetic moment (e.g., Nobile et al. 2012). In our area of study, the 2009 Harrat Lunayyir swarm, which occurred $\geq 50 \mathrm{~km}$ southeast of the 2017 swarm, was caused by an ascending magma intrusion that, using InSAR data, was estimated to be $\geq 10 \mathrm{~km}$ long, with a volume of $0.13 \mathrm{~km}^{3}$, and stops at $\sim 1$ $\mathrm{km}$ below the surface (Pallister et al., 2010). Furthermore, the dike intrusion produced over $\sim 1.5 \mathrm{~m}$ of SW-NE extension as well as $60 \mathrm{~cm}$ of graben subsidence above the intrusion (Jónsson 2012). Pallister et al. (2010) reported that $\geq 93 \%$ of the deformation observed during the 2009 dike intrusion was aseismic. Therefore, the amplitude and pattern of the ground deformation could give valuable information about the origin of the seismicity.

Geodetic remote sensing techniques, such as InSAR, allow measuring ground deformation even in areas where ground-based networks are not 
present, as the case of the area affected by the 2017 swarm. We, therefore, used InSAR to detect any ground deformation in the area to constrain the results obtained by the analysis of the seismic data. We selected SAR scenes from the Sentinel-1 A/B satellites acquired between January 2017 and January 2019, a total of 51 images from ascending track 87 and 89 images from descending track 123. We processed 100 ascending and 266 descending orbit interferograms with spatial baselines smaller than $200 \mathrm{~m}$ and temporal baselines up to 36 days (supplementary Figure S7).

Due to high coherence, the resulting interferograms could be easily unwrapped and used to calculate deformation rate maps in the line of sight (LOS) of the satellites with the Small Baseline Subset (SBAS) technique (e.g., Samsonov 2017). The initial rate maps showed deformation correlated to topography, indicating significant elevation-related atmospheric delays. We reduced these signals by estimating linear correlation coefficients between elevation and the signal and subtracted the results from the rate maps (e.g., Neelmeijer et al. 2018). However, we were not able to remove completely the signal-topography correlation as evident in the southern part of the ascending deformation rate map (Figure 10a). The final deformation rate maps mostly show smooth variations of $\pm 0.5 \mathrm{~cm} / \mathrm{yr}$ (Figure 10), which are due to the noise of the interferograms that could not be fully removed in the timeseries analysis. The only clear deformation signal is located $\sim 10 \mathrm{~km}$ north of the swarm location (Figure 10b), in a narrow WNW-ESE elongated area that corresponds to an ephemeral riverbed (Wadi). This area shows up to 1 $\mathrm{cm} / \mathrm{yr}$ of displacement toward the satellite for both viewing geometries. This corresponds to an uplift of $1.2 \mathrm{~cm} / \mathrm{yr}$, which might be attributed to water 
level changes of the shallow aquifer. No clear deformation is observed in or around the area of the 2017 seismic swarm in these rate maps.

We use analytical models to quantify the expected ground deformation due to the seismic swarm. The relocated events are distributed over a 5 $\mathrm{km} \times 9 \mathrm{~km}$ planar-like volume that dips $\sim 15^{\circ} \mathrm{SSW}$ with its upper edge at $\sim 5 \mathrm{~km}$ depth. Given this geometry, a normal focal mechanism of the main events and the total seismic moment of $\sim 12.5 \times 10^{14} \mathrm{Nm}$, less than half a mm of surface displacements would be expected, i.e., less than what is detectable by the InSAR technique. Using the spatial extent of the current swarm as dimensions for a possible dike intrusion $(5 \mathrm{~km}$ long, $9 \mathrm{~km}$ wide at $5 \mathrm{~km}$ depth) and assuming an opening of $0.5 \mathrm{~m}$, which corresponds to $\sim 1 / 6$ of the volume of the 2009 intrusion, the predicted surface deformation is $\sim 2$ $\mathrm{cm}$ that would have been detected by InSAR. However, there is no evident ground deformation in the two InSAR rate maps (Figure 10). Therefore, the InSAR data analysis suggests that the seismic swarm was not accompanied by a magmatic intrusion.

\section{Discussion}

The current seismic analysis focuses on one of the most recent earthquake activity nearby Harrat Lunayyir area. Since February 2017, a swarm located to the north of Harrat Lunayyir is being recorded continuously, with a maximum magnitude of $M_{W}$ 3.60. We study the source properties using the available seismic records, applying double-difference algorithm, full-waveform moment tensors inversion, frequency index analysis, and stress drop estimations. 
To identify the activity source-type, we propose a well-defined workflow (supplementary Figure S8), applying a suite of seismological tools. Additionally, we advocate analyzing InSAR images to complement the seismological data and results. This flow-chart proposed in this study may serve as guidance for future studies on seismic swarms, to characterize and quantify their properties using multiple datasets and analysis techniques to help discriminate volcanic from non-volcanic events.

In a regional geographic context, the shield area of the Red Sea flanks is active with a continuous background seismicity. Different kinds of seismic events have been observed in this area as reported in table S1 with some of their main characteristics (supplementary Figure S1).

Harratt Lunayyir volcanic field ( 50 km SE of our study area) hit by a seismic swarm, with intense rate in the first four months between April and July 2009. In this period, more than 30k recorded events struck the area with many events of $M_{L}>4$ (e.g., Pallister et al. 2010, Baer \& Hamiel 2010, AlAmri et al. 2012). Several seismic and geodetic studies have confirmed the magmatic intrusion origin as the primary cause of this activity (e.g., Jónsson 2012, Duncan \& Al-Amri 2013, Koulakov et al. 2014 and 2015, Xu et al. 2016). It is worth mentioning that Harrat Lunayyir region is still under a steady background seismicity (Figure 2a).

The ongoing activity of our main focus here started in February 8th, 2017, with seven largest events between $M_{L} 3.0$ to 3.73 , where all of these relatively large events occurred during the first four months since the swarm started. Additionally, another swarm started in October 2018 around Umm-Lujj area, $\sim 25 \mathrm{~km}$ SW of Harrat Lunayyir, with a maximum magnitude of $M_{L} 3.70$. 
To compare between three swarms in the study region, we start with applying the first step in our flow-chart (statistics with MFD). This comparison study was not conclusive because of the lack of complete datasets (mainly limited catalog for the located events using the standard network approach, in addition to very few available waveforms). Nevertheless, its results turn out to conduct a first-order comparison as it indicates that swarms located to the SW (2018) and SE (2007) of Lunayyir are more associated with relative high b-values, analogous to the background seismicity. Our analysis reveals the b-value varies between 0.85 and 1.3. This high b-value may be associated with transporting fluids out of the deep volcanic system in the region, as interpreted in previous work of Blanchette et al. (2018). Farrell et al. (2009) also concluded that high b-value (up to $1.3 \pm 0.1$ ) is attributed to the presence of a high thermal gradient due to fluids emplacement, while the low b-value (as low as $0.6 \pm 0.1$ ) might be caused by crustal stress from regional loading.

Generally, the b-value could be also connected to the rock physical properties. For instance, Wyss et al. (1997) and Wiemer et al. (1998) pointed out that low b-values could correspond to breaking asperities while the high bvalues correspond to creeping sections of faults or due to magmatic processes, where seismicity may also be dominated by the creation of new fractures under stress build-up. According to Urbancic et al. (1992) and Wyss et al. (1997), an increase in applied shear stress will be decreasing the b-value.

The high b-value could also be indicative of a relative low stress regime resulting from the energy releases by continuous earthquake activities in the vicinity (e.g., Farrell et al. 2009). Another scenario, specifically valid for 
the SW 2018 swarm, comes from being close to the sea which may cause the presence of fluids in the fault system. In contrast, we found the northern area of the 2017 swarm is characterized by low b-values (0.73 \pm 0.03 , Figure 2). This relatively low b-value can be interpreted as a hint of evidence for a high stress regime associated with a dominant extension, which is expected to be found in such intraplate tectonic settings (e.g. Wolfe et al. 2003, Keir et al. 2009). In this study, the observed b-values difference between the northern and southern swarms tend to attribute them to different origins.

The relative relocation for the 2017 swarm show clustering of the largestmagnitude and earliest events at deeper mid-crustal levels different from the shallow, small-magnitudes events which taken place later in time. This shows an upward time migration of the large early events to form the later (longlasting) small-size upper crustal events (Figure 3). These results highlight the presence of a fault zone that is accommodating an active strain within the regional Najd Fault System. This observation may imply an evidence for a potentially reactivation mechanism within this Precambrian shear zone.

To estimate the relocation errors, we applied a sensitivity analysis by backprojecting the incident rays of the main event. We calculate the expected phase travel times and ray parameters. The predicted values agree well with the fk-analysis, confirming the relocated hypocenter of this event of interest. The uncertainty in slowness values is small $\left(0.45 \mathrm{~s} /{ }^{\circ}\right)$, where the backazimuth values have $\sim 1^{\circ}$ difference. A source of such shift is attributed to the use of only one pair of event-station for the synthetics while using several stations in the fk measurements, however, also the lack of an accurate 3D velocity model contributes to the location uncertainty. 
The full waveform moment tensor inversion using the largest event of the 2017 swarm shows a typical quality of waveform fits from the traces presented in Figure 5. We used all available stations (supplementary Figure S2), thereby minimizing the effect of the model uncertainty along any given raypath on the moment tensor solution. Despite relying on this $M_{W} 3.6$ event in the interpretation, we also applied the inversions on eight more events of this swarm. We plotted all the inversions results using the fundamental lune plot (Figure 6a). For some waveforms, the amplitude mismatch between observed and synthetic low-frequency signals may contain information about the large-scale, structural-related, corrections needed to better calibrate the velocity models.

We point out that a reliable velocity model is vital to pursue the full waveform inversion of moment tensor as well as for an accurate relative relocation. The two velocity models examined in this study belong to the SGS regional model as reported in Soliman et al. (2019), in addition to the local model of Harrat Lunayyir developed by Tang et al. (2016) (Figure 3). We selected the model of Tang et al. (2016), which is constructed using both Pand S-waves receiver functions and surface waves dispersion measurements to constrain the structure underneath the study area. This velocity model has also some finer details, as the imaged low-velocity seismic perturbations of the mid crust, which might helped for a better relocation and signified the waveforms fits for the high-frequency moment tensor solution.

We examine earthquake source properties in terms of stress drop $(\Delta \sigma)$ which is proportional to the total seismic moment and rupture size, and could help defining the tectonic environment (e.g., large stress drops are related to 
more high-frequency energy release). In our analysis for the largest three events of the 2017 swarm, we perform a grid-search to find the parameters that best model the spectrum characteristic; $\omega_{0}$, and $f_{c}$. Our estimates of these parameters indicate azimuthal variations around event hypocenters. The median of $\left(f_{c}\right)$ and $(\Delta \sigma)$ around $2 \pi$ circumference ranges from $\sim 2.3$ - $3.2 \mathrm{~Hz}$ and $\sim 4.4-6.9 \mathrm{MPa}$, respectively. This result confirms a similar finding for intraplate events, by Kanamori \& Anderson (1975), and Allmann \& Shearer (2009).

Additionally, we apply FI analysis which calculates the mean amplitude of two spectral bands (high $\left(A_{h f}\right)$ and low $\left(A_{l f}\right)$ ranges) to help describing the relative spectral content of a single event. This is a useful quantity to analyze spectral properties and trends. For instance, Buurman and West (2010) used $A_{h f}$ of $10-20 \mathrm{~Hz}$, and $A_{l f}$ of $1-2 \mathrm{~Hz}$, finding that low $F I$ values are a good indicator of impending eruption at Augustine Volcano in 2006. Our analysis shows that a majority of spectral energy is limited between 10 and $20 \mathrm{~Hz}$ at the 2017 swarm, and thus the spectral bands were extended to $10-30 \mathrm{~Hz}$ for $A_{h f}$, and $\sim 0.015-0.045 \mathrm{~Hz}$ for $A_{l f}$. Inspection on the example shown in Figure 9 indicates the spectral difference between the three swarms of 2009, 2017 and 2018. Checking this figure, the upper panel (the 2017 swarm) has a relatively higher frequency spectrum and thus higher FI than the lower panel (the 2009 swarm, Harrat Lunayyir intrusion event). This method and its result provide further evidence for the tectonic origin of the 2017 swarm. The main event of the 2018 shows a hybrid behaviour. The spectra shows no significant low-frequency signal but it tends to have considerable amount of energy between the two separated windows of high-low frequency ranges. 
Using InSAR imaging, the deformation rate maps show smooth variations between $\sim \pm 0.5 \mathrm{~cm} / \mathrm{yr}$ (Figure 10), which are due to the noise of the interferograms that could not be fully eliminated during the processing. Magma intrusion at shallow depth, generally causes ground deformations that can be observed by geodetic techniques such as InSAR (e.g. Biggs and Pritchard, 2017). As indicated from the rate maps, no significant signal of deformation is observed on the surface above the events' focal points, suggesting that the swarm is not associated to magmatic processes.

To summarize, the results clearly indicate crustal seismicity with a narrow E-W ( 500 m wide), and steeply south dipping structure beneath this area. Independent evidence from Szymanski at al. (2016) confirms the existence of fault trace exposure at the relocated events E-W surface corridor. All results out of the above analyses may imply an opening mechanism due to the regional stress fields of the Red Sea tectonic regime which is also evident in the stress inversion result (Figure 6b). Thus, our interpretation suggests a mechanism of extensional faulting on a pre-existing weakness zone (Najd Fault System), proposing that the 2017 swarm activity is mostly a tectonic deformation with overprinting a dipping structural fabric, resulting in a fracture developed in this old transform system.

\section{Conclusions}

We conclude that the occurrence of the 2017 earthquake swarm ( 50 km NW of Harrat Lunayyir boundaries) is not directly associated with a magmatic cause. In this analysis, we implement various integrated approaches 
in sequential workflow (supplementary Figure S9) that provides a road-map for source parameter estimates. By applying these techniques, ruling out particular causes of seismicity gradually in a step by step process by a comprehensive, integrated data analysis approach is followed.

This series of analyses determines whether, or not, the seismic sequences are caused by fluid-driven processes as they may occur in any area susceptible to volcano-earthquakes interactions.

For the swarm analyzed here, our results confirm a localized crustal tectonic deformation. Our conclusion comes mainly from the high-frequency content of the events, the fault-like structure from the relative relocation which confirms an upward migration, and finally from the focal mechanism solutions.

We conclude that the current extensional-mechanism seismicity of north of Harrat Lunayyir might be attributed to the regional stress fields of the Red Sea stretching continental crust. 
${ }_{613} \quad$ Acknowledgments

${ }_{614}$ Special thanks to Derek Keir, Finnigan Illsley-Kemp (University of Southamp${ }_{615}$ ton), Jose A. Lopez Comino (KAUST and now at University of Granada), 616 and Kiran K. Thingbaijam (KAUST) for the fruitful discussions which in617 clude suggesting FI technique and enhancing the moment tensor inversion ${ }_{618}$ and stress drop analyses. We wish to thank Felix Waldhauser (Lamont${ }_{619}$ Doherty Earth Observatory) for providing the latest unpublished version of 620 his code (HypoDD of 2019). Our project received financial support from ${ }_{621}$ King Abdullah University of Science and technology (KAUST) under the 622 CRG grant (ORS-2016-CRG5-3027-0). All waveform data were obtained ${ }_{623}$ through the Saudi Geological Survey (SGS) and is available from Harvard ${ }_{624}$ Dataverses webpage (https://doi.org/10.7910/dvn/kw4zfx). 


\section{References}

1. Abdelfattah, A.K., A. Al-Amri, A.K. Abd el-aal, Faisal K. Zaidi, M. Fnais, S. Almadani, N. Al-Arifi, (2017). The 23 January 2014 Jizan earthquake and its tectonic implications in southwestern Saudi Arabia, Tectonophysics, Volumes 712-713, Pages 494-502, ISSN 0040-1951, https://doi.org/10. 1016/j.tecto.2017.05.034.

2. Abdelfattah, A.K., Al-amri, A., Sami Soliman, M. et al, (2020). An analysis of a moderate earthquake, eastern flank of the Red Sea, Saudi Arabia. Earth Planets Space 72, 34. https://doi.org/10.1186/s40623-020-01159-5

3. Abercrombie R.E., (2015). Investigating uncertainties in Empirical Green's function analysis earthquake source parameters, J. geophys. Res., 120(6), 4263-4377.

4. Aki, K., and Richards, P.G., 1980, Quantitative seismology: New York, W.H. Freeman, 700 p.

5. Al-Amri, A. M., M. S. Fnais, K. Abdel-Rahman, S. Mogren, and M. AlDabbagh (2012), Geochronological dating and stratigraphic sequences of Harrat Lunayyir, NW Saudi Arabia, Int. J. Phys. Sci., 7(20), 2791-2805.

6. Al-Damegh, K., Abou Elenean, K., Hussein, Hesham \& Rodgers, Arthur. (2009). Source mechanisms of the June 2004 Tabuk earthquake sequence, Eastern Red Sea margin, Kingdom of Saudi Arabia. Journal of Seismology. 13. 561-576. https://doi.org/10.1007/s10950-008-9148-5.

7. Al-Damegh, K., , Hussein, Hesham, Nasser Al-Arifi, S, Moustafa, Sayed \& Moustafa, Moustafa. (2012). Focal mechanism of Badr earthquake, Saudia 
Arabia of August 27, 2009. Arabian Journal of Geosciences - ARAB J GEOSCI. 5. https://doi.org/10.1007/s12517-010-0200-8.

8. Allmann B.B., \& Shearer P.M., 2009. Global variations of stress drop for moderate to large earthquakes, J. geophys. Res., 114, https://doi:10. 1029/2009JB005821.

9. Alsaker, A., Kvamme, L.,B., Hansen, R.,A., Dahle A., Bungum H., (1991). The $M_{L}$ scale in Norway. Bull Seismol Soc Am 81(2):379-398

10. Badawy, A., Elnashar, S., Abdelfattah, A., (2008). Microearthquakes and Neotectonics of Abu-Dabbab, Eastern Desert of Egypt. Seismological Research Letters - SEISMOL RES LETT. 79. 55-67. https://doi.org/10. 1785/gssrl.79.1.55.

11. Baer, G., Hamiel Y. Shamir G. Nof R. , (2008). Evolution of a magma-driven earthquake swarm and triggering of the nearby Oldoinyo Lengai eruption, as resolved by InSAR, ground observations and elastic modeling, East African Rift, 2007, Earth planet. Sci. Lett., 272, 339-352.

12. Baer, G., and Y. Hamiel (2010), Form and growth of an embryonic continental rift: InSAR observations and modeling of the 2009 western Arabia rifting episode, Geophys. J. Int., 182, 155-167.

13. Bianco, F., E. Del Pezzo, G. Saccorotti, G. Ventura, (2004), The role of hydrothermal fluids in triggering the July-August 2000 seismic swarm at Campi Flegrei, Italy: evidence from seismological and mesostructural data. Journal of Volcanology and Geothermal Research, Volume 133, Issues 1-4, pages 229-246, ISSN 0377-0273, https ://doi .org/10.1016/S0377-0273(03) 00400-1. 
14. Biggs, J., \& Pritchard, M. E., (2017), Global Volcano Monitoring: What Does It Mean When Volcanoes Deform?. Elements ; 13 (1): 17-22. https: //doi.org/10.2113/gselements.13.1.17

15. Blanchette, A. R., Klemperer, S. L., Mooney, W. D., and Zahran, H. M. (2018). Two-stage Red Sea rifting inferred from mantle earthquakes in Neoproterozoic lithosphere. Earth Planet. Sci. Lett. 497, 92-101. https: //doi.org/10.1016/j.epsl.2018.05.048.

16. Blasband, B., S. White, P. Brooijmans, H. De Boorder and W. Visser (2000). Late Proterozoic extensionalcollapse in the Arabian-Nubian Shield. Journal of the Geological Society, London, v. 157,p. 615-628.

17. Boatwright J., \& Fletcher J.B.(1984). The partition of radiated energy between P and S waves, Bull. seism. Soc. Am., vol. 74 2(pg. 361-376)

18. Bormann, P., (2012) Magnitude calibration formulas and tables, comments on their use and complementary data. In: Bormann P (ed) New Manual of Seismological Observatory Practice 2 (NMSOP-2). Deutsches GeoForschungsZentrum GFZ, Potsdam, pp 1-19. https://doi.org/10.2312/ GFZ.NMSOP-2_DS_3.1

19. Boyd O. S., McNamara D. E., Hartzell S., \& Choy G., (2017). Bull. Seismol. Soc. Am. 107.

20. Buurman, H., and M. West (2010), Seismic precursors to volcanic explosions during the 2006 eruption of Augustine Volcano, in The 2006 Eruption of Augustine Volcano, USGS Professional Paper 1769.

21. Brune J.N., (1970). Tectonic stress and the spectra of seismic shear waves from earthquakes, J. geophys. Res., vol. 75 (pg. 4997-5009). 
22. Camp, V.E., Hooper, P.R., Roobol, M.J. et al. Bull Volcanol (1987) 49: 489. https://doi.org/10.1007/BF01245475.

23. Camp, V. E., and M. J. Roobol (1992), Upwelling asthenosphere beneath western Arabia and its regional implications, J. Geophys. Res., 97(B11), $15,255-15,271$.

24. Chang, S.-J., M. Merino, S. Van der Lee, S. Stein, and C. A. Stein (2011), Mantle flow beneath Arabia offset from the opening Red Sea, Geophys. Res. Lett., 38, L04301, https://doi.org/10.1029/2010GL045852.

25. Coleman, R. G., R. T. Gregory, and G. F. Brown (1983), Cenozoic Volcanic Rocks of Saudi Arabia, U.S. Geol. Surv. Open-file Rep., 83-788, and Saudi Arabian Deputy Minist. Miner. Resourc., Open File Rep., USGS- OF-03-93.

26. de Lorenzo S., Zollo A., Zito G., (2010). Source, attenuation, and site parameters of the 1997 Umbria-Marche seismic sequence from the inversion of $\mathrm{P}$ wave spectra: a comparison between constant QP and frequencydependent QP models. J Geophys Res Solid Earth 115(B9):B09306. https : //doi.org/10.1029/2009JB007004.

27. Dreger, D. S, H. Tkalcic, and M. Johnston (2000). Dilational processes accompanying earthquakes in the Long Valley Caldera, Science 288, 122125.

28. Duncan, R. A., and A. M. Al-Amri (2013), Timing and composition of volcanic activity at Harrat Lunayyir, western Saudi Arabia, J. Volcanol. Geotherm. Res., 260, 103-116.

29. Dziak, R. P., Chadwick, W. W., Jr, Fox, C. G., \& Embley, R. W. (2003). Hydrothermal temperature changes at the southern Juan de Fuca Ridge 
associated with $M_{W} 6.2$ Blanco Transform earthquake. geology 31, 119-122.

30. Dzurisin, D., 2007, Volcano Deformation - Geodetic Monitoring Techniques, Berlin, Springer, Springer-Praxis Books in Geophysical Sciences, 441 p.

31. Edwards, B., A. Rietbrock, J. J. Bommer, and B. Baptie (2008), The acquisition of source, path, and site effects from microearthquake recordings using Q tomography: Application to the United Kingdom, Bull. Seismol. Soc. Am., 98, 1915-1935, https://doi:10.1785/0120070127.

32. Eshelby J.D., (1957). The determination of the elastic field of an ellipsiodal inclusion, and related problems, Proc. R. Soc. Lond. A, vol. 241 1226(pg. 376-396).

33. Farrell, J., Husen, S., Smith, R.B., (2009). Earthquake swarm and b-value characterization of the Yellowstone volcano-tectonic system. J. Volcanol. Geotherm. Res., 188 (1-3) (2009), pp. 260-276, ISSN 0377-0273, https: //doi.org/10.1016/j. jvolgeores. 2009.08.008.

34. Ford S.R., Dreger D.S., Walter W.R. (2009). Identifying isotropic events using regional moment tensor inversion, J. geophys. Res., 114, B01306.

35. Guglielmino, F., Bignami C., Bonforte, A., Briole, P., Obrizzo F., Puglisi, G., Stramondo, S., Wegmüller, U.,(2011). Analysis of satellite and in situ ground deformation data integrated by the SISTEM approach: The April 3, 2010 earthquake along the Pernicana fault (Mt. Etna - Italy) case study, Earth and Planetary Science Letters, Volume 312, Issues 3-4, , Pages 327336, ISSN 0012-821X, https://doi.org/10.1016/j.eps1.2011.10.028.

36. Hainzl, S., Seismicity patterns of earthquake swarms due to fluid intrusion and stress triggering, Geophysical Journal International, Volume 159, 
Issue 3, December 2004, Pages 1090-1096, https://doi.org/10.1111/j. 1365-246X. 2004.02463.x.

37. Hansen, S. E., S. Y. Schwartz, H. R. DeShon, and V. González (2006), Earthquake Relocation and Focal Mechanism Determination Using Waveform Cross Correlation, Nicoya Peninsula, Costa Rica, Bull. Seismol. Soc. Am., 96, 1003-1011.

38. Hayashi, Y., \& Morita, Y. (2003). An image of a magma intrusion process inferred from precise hypocentral migrations of the earthquake swarm east of the Izu Peninsula. Geophysical Journal International, 153(1), 159-174. https://doi.org/10.1046/j.1365-246X.2003.01892.x

39. Hill, D. P. ( 1977), A model for earthquake swarms, J. Geophys. Res., 82( 8), 1347-1352, https://doi.org/10.1029/JB082i008p01347.

40. Hill, D. P., Dawson, P., Johnston, M. J. S., Pitt, A. M., Biasi, G., and Smith, K., (2002), Very-long-period volcanic earthquakes beneath Mammoth Mountain, California, Geophys. Res. Lett., 29(10), https://doi.org/10. 1029/2002GL014833, 2002.

41. Ichinose, G., Anderson, J., Smith, K. and Zeng, Y., 2003: Source parameters of Eastern California and Western Nevada earthquake from regional moment tensor inversion, Bull. seism. Soc. Am., 93, 61-84.

42. Johnson, S.P., Cutten, H.N.C., Muhongo, S. , and De Waele, B. Neoarchaean magmatism and metamorphism of the western granulites in the central domain of the Mozambique belt, Tanzania: U-Pb shrimp geochronology and PTestimates. Tectonophysics, 375 (2003), pp. 125-145 
43. Jónsson, S. (2012), Tensile rock mass strength estimated using InSAR, Geophys. Res. Lett., 39, L21305, https://doi.org/10.1029/2012GL053309.

44. Jost, M., \& Herrmann, R., (1989). A Student's Guide to and Review of Moment Tensor. Seismol. Res. Lett. 60(2): 37-57.

45. Kanamori, H., \& D. Anderson (1975). Theoretical basis of some empirical relations in seismology, Bull. Seismol. Soc. Am., 65(5), 1073-1095.

46. Keir, D., Bastow, I. D., Whaler, K. A., Daly, E., Cornwell, D. G., \& Hautot, S. ( 2009), Lower crustal earthquakes near the Ethiopian rift induced by magmatic processes, Geochem. Geophys. Geosyst., 10, Q0AB02, doi:10.1029/2009GC002382.

47. Koulakov, I., S. El Khrepy, N. Al-Arifi, I. Sychev, and P. Kuznetsov (2014), Evidence of magma activation beneath the Harrat Lunayyir basaltic field (Saudi Arabia) from attenuation tomography, Solid Earth, 5, 873-882.

48. Legrand, L., A Calahorrano, B Guillier, L Rivera, M Ruiz, D Villagómez, H Yepes, (2002). Stress tensor analysis of the 1998-1999 tectonic swarm of northern Quito related to the volcanic swarm of Guagua Pichincha volcano, Ecuador, Tectonophysics, Volume 344, Issues 1-2, 2002, Pages 15-36, ISSN 0040-1951, https://doi.org/10.1016/S0040-1951(01)00273-6.

49. Latter, J.H., 1980, Volcanic earthquakes and their relationship to eruptions at Ruapehu and Ngauruhoe volcanoes: Journal of Volcanology and Geothermal Research, v.9, p. 293-309.

50. Lomax, A., J. Virieux, P. Volant, and C. Berge (2000), Probabilistic earthquake location in 3D and layered models: Introduction of a MetropolisGibbs method and comparison with linear locations, in Advances in Seismic 
Event Location, edited by C. H. Thurber and N. Rabinowitz, pp. 101-134, Kluwer Academic, Amsterdam.

51. Madariaga R., (1976). Dynamics of an expanding circular fault, Bull. seism. Soc. Am., vol. 66 3(pg. 639-666).

52. Manga, M., \& Brodsky, E., (2006). Seismic Triggering of Eruptions in the Far Field: Volcanoes and Geysers. Annual Review of Earth and Planetary Sciences. 34. 263-291. https://doi.org/10.1146/annurev.earth.34. 031405.125125.

53. McNutt, S.R., 2002, Volcano seismology and monitoring for eruptions, chap. 25 of Lee, W.H.K., Kanamori, H, Jennings, P.C., and Kisslinger, C., eds, International handbook of earth- quake and engineering seismology: Academic Press, v. 81A.

54. Mukhopadhyay, B., S. Mogren, M. Mukhopadhyay, and S. Dasgupta (2012), Incipient status of dyke intrusion in top crust - evidences from the Al-Ays 2009 earthquake swarm, Harrat Lunayyir, SW Saudi Arabia, Geom. Nat. Hazard. Risk, 4, 30-48.

55. Neelmeijer, J., Schöne, T., Dill, R., Klemann, V., \& Motagh, M. (2018). Ground Deformations around the Toktogul Reservoir, Kyrgyzstan, from Envisat ASAR and Sentinel-1 Data-A Case Study about the Impact of Atmospheric Corrections on InSAR Time Series. Remote Sensing, 10(3), 462.

56. Nobile, A., Pagli, C., Keir, D., Wright, T. J., Ayele, A., Ruch, J., and Acocella, V. (2012), Dike-fault interaction during the 2004 Dallol intrusion at the northern edge of the Erta Ale Ridge (Afar, Ethiopia), Geophys. Res. 
Lett., 39, L19305, doi:10.1029/2012GL053152.

57. Nobile, A., Cao Y., Youssof, M., Trippanera, D., Passarelli, L., and Jónsson, S., (2020). Post-diking deformation in Harrat Lunayyir (Saudi Arabia) from InSAR. Geophys. Res. Abstr. 21:EGU2020-8272.

58. Oth, A. (2013). On the characteristics of earthquake stress release variations in Japan, Earth Planet. Sci. Lett., 377-378, 132-141, doi:10.1016/j.epsl.2013.06.037.

59. Pallister, J. S. (1987), Magmatic history of Red Sea rifting, Geol. Soc. Am. Bull., 98, 400-417.

60. Pallister, J. S., et al. (2010), Broad accumulation of rift-related extension recorded by dyke intrusion in Saudi Arabia, Nature Geosci., 3, https:// doi.org/10.1038/NGE0966.

61. Passarelli, L., Hainzl, S., Simone Cesca, Francesco Maccaferri, Marco Mucciarelli, Dirk Roessler, Fabio Corbi, Torsten Dahm, Eleonora Rivalta, Aseismic transient driving the swarm-like seismic sequence in the Pollino range, Southern Italy, Geophysical Journal International, Volume 201, Issue 3, June, 2015, Pages 1553-1567, https://doi.org/10.1093/gji/ggv111

62. Pollard, D.D., Delaney, P.T., Duffield, W.A., Endo, and Okamura, A.T., 1983. Surface deformation in volcanic rift zones. In: P. Morgan and B.H. Baker - Developments in Geotectonics, 1983 vol. 19 pp. 541-584. https: //doi.org/10.1016/B978-0-444-42198-2.50036-5.

63. Ritsema, J., and Lay, T. ( 1995), Long-period regional wave moment tensor inversion for earthquakes in the western United States, J. Geophys. Res., 100( B6), 9853-9864, doi:10.1029/95JB00238. 
64. Riedesel, M. A. \& Jordan, T. H. Display and assessment of seismic moment tensors. Bulletin of the Seismological Society of America 79, 85-100 (1989).

65. Roland, E., McGuire, J. J, Earthquake swarms on transform faults, Geophysical Journal International, Volume 178, Issue 3, September 2009, Pages 1677-1690, https://doi.org/10.1111/j.1365-246X.2009.04214.x

66. Roobol M.J., Bankher K, Bamufleh S (1994). Geothermal anomalies along the MMN volcanic line including the cities of Al-Madinah Al- Munawwarah and Makkah Al-Mukarramah. Saudi Arabian Deputy Ministry for Mineral Resources Confidential Report DGMR- MADINAH- CR-15-2, p. 95.

67. Rubin, A.M., and Pollard, D.D., 1988, Dike-induced faulting in rift zones of Iceland and Afar: Geology, 16, 413-417.

68. Saibi, H., Saad Mogren, Manoj Mukhopadhyay, Elkhedr Ibrahim, (2019). Subsurface imaging of the Harrat Lunayyir 2007-2009 earthquake swarm zone, western Saudi Arabia, using potential field methods, Journal of Asian Earth Sciences, Volume 169, Pages 79-92, ISSN 1367-9120, https://doi. org $/ 10.1016 / j \cdot j$ seaes. 2018.07.024.

69. Samsonov, S. V., \& d'Oreye, N. (2017). Multidimensional Small Baseline Subset (MSBAS) for Two-Dimensional Deformation Analysis: Case Study Mexico City. Canadian Journal of Remote Sensing, 43(4), 318-329.

70. Shearer, P. M., Prieto, G. A., and Hauksson, E., (2006). Comprehensive analysis of earthquake source spectra in Southern California. J. Geophys. Res., 111, B06303,https://doi:10.1029/2005JB003979.

71. Sigmundsson, F., et al., (2018). Magma movements in volcanic plumbing systems and their associated ground deformation and seismic patterns: ex- 
amples from Iceland. Burchardt, S., (Ed.), Volcanic and Igneous Plumbing Systems, Elsevier, pp. 285-322

72. Soliman, M., Hani, M. Z. , Elhadidy, S. Y. \& Alraddadi, W. (2019). Evaluation of Saudi National Seismic Network (SNSN) detectability. Arabian Journal of Geosciences. 12. 330. https://doi .org/10.1007/s12517-019-4423-z.

73. Szymanski, E., D. F. Stockli, P. R. Johnson, and C. Hager (2016), Thermochronometric evidence for diffuse extension and two-phase rifting within the Central Arabian Margin of the Red Sea Rift, Tectonics, 35, 2863-2895, https://doi.org/10.1002/2016TC004336.

74. Tang, Z., Jordi J., Zahran H., and Mai P. M., 2016. The lithospheric shearwave velocity structure of Saudi Arabia: Young volcanism in an old shield, Tectonophysics $680,8-27$.

75. Tape, Walter \& Tape, Carl. (2019). The eigenvalue lune as a window on moment tensors. Geophysical Journal International. 216. 19-33. https: //doi.org/10.1093/gji/ggy373.

76. Trippanera, D., Ruch, J., Passone, L. \& Jónsson, S., (2019). Structural Mapping of Dike-Induced Faulting in Harrat Lunayyir (Saudi Arabia) by Using High Resolution Drone Imagery. Frontiers in Earth Science 7, 168.

77. Tusa, G., Brancato, A. \& Gresta, S., (2006a). Source parameters of microearthquakes in Southeastern Sicily, Italy, Bull. seism. Soc. Am., 96, https://doi.org/10.1785/0120050071.

78. Tusa, G., Brancato, A., Gresta, S. and Malone, S.D., (2006b), Source parameters of microearthquakes at Mount St Helens (USA). Geophysical Journal 
International, 166: 1193-1223. https://doi.org/10.1111/j.1365-246X. $2006.03025 \cdot x$

79. Urbancic, T.I., Trifu, C.I., Long, J.M., \& Young, R.P.,(1992). Space-time correlations of b-values with stress release, PAGEOP, 139, 449-462.

80. Vavryčuk, Vaclav. (2014). Iterative joint inversion for stress and fault orientations from focal mechanisms. Geophysical Journal International. 199. 69-77. 10.1093/gji/ggu224.

81. Vidale, J. E., and Shearer, P. M. ( 2006), A survey of 71 earthquake bursts across southern California: Exploring the role of pore fluid pressure fluctuations and aseismic slip as drivers, J. Geophys. Res., 111, B05312, https: //doi.org/10.1029/2005JB004034.

82. Waite, G. R. and R. B. Smith (2002). Seismic evidence for fluid migration accompanying subsidence of the Yellowstone Caldera. Journal of Geophysical Research. 107. 2177. 10.1029/2001JB000586.

83. Waldhauser, F., and W. L. Ellsworth, 2000. A Double-Difference Earthquake Location Algorithm: Method and Application to the Northern Hayward Fault, California." BSSA, 90, p. 1353- 1368.

84. White, R.A., Wendy A. McCausland, A process-based model of pre-eruption seismicity patterns and its use for eruption forecasting at dormant stratovolcanoes, Journal of Volcanology and Geothermal Research, 2019, ISSN 0377-0273, https://doi.org/10.1016/j.jvolgeores.2019.03.004.

85. Wiemer S., McNutt S.R., \& Wyss M., (1998). Temporal and three-dimensional spatial analysis of the frequency-magnitude distribution near Long Valley caldera, California, Geophys. J. Int., 134, pp. 409-421 
86. Wiemer, S. and Wyss, M.,(2000). Minimum magnitude of complete reporting in earthquake catalogs: Examples from Alaska, the Western United States, and Japan, Bull. Seismol. Soc. Am., 90, 859-869, https://doi. org/10.1785/0119990114.

87. Woessner, J. and Wiemer, S., (2005) Assessing the Quality of Earth- quake Catalogues: Estimating the Magnitude of Complete- ness and Its Uncertainty, Bull. Seism. Soc. Am., 95, 684-698, https://doi.org/10.1785/ 0120040007.

88. Wolfe, C.J., Okubo, P.G., Shearer, P.M. (2003), Mantle fault zone beneath Kilauea Volcano, Hawaii, Science, 300 , pp. 478-480.

89. Wyss, M., Shimazaki, K., \& Wiemer, S., (1997). Mapping active magma chambers by b-value beneath the off- Ito volcano, Japan, J. Geophys. Res., 102, 20413-20422.

90. Xu, W., S. Jónsson, F. Corbi, and E. Rivalta (2016), Graben formation and dike arrest during the 2009 Harrat Lunayyir dike intrusion in Saudi Arabia: Insights from InSAR, stress calculations and analog experiments, J. Geophys. Res. Solid Earth, 121, 2837-2851, https://doi.org/10.1002/ $2015 J B 012505$.

91. Zeng, Y., and Anderson, J.G. (1995). A Method for Direct Computation of the Differential Seismogram with Respect to the Velocity Change in a Layered Elastic Solid, BSSA, Vol.85, No.1, pp.300-307. 


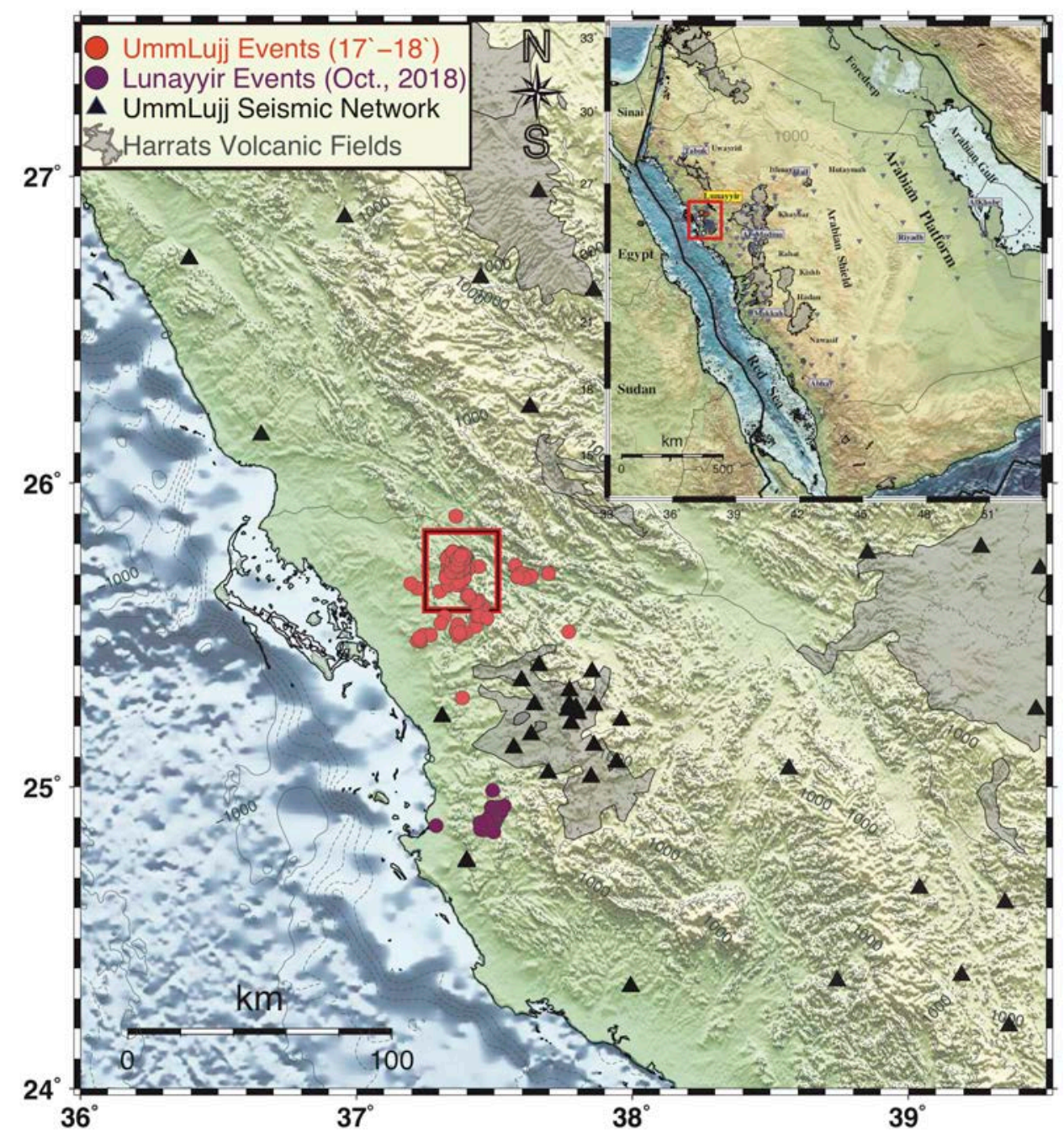

Figure 1: Location map for Lunayyir swarms and local seismic stations. This seismicity is shown by the preliminary location solution using the standard network (hypoinverse) algorithm (circles in red for the northern swarm which started in Feb. 2017, and in purple for the southern swarm which started in Oct. 2018). The inset in the upper right corner shows the Arabian Peninsula with the entire Saudi National Seismic Network (SNSN, details in supplementary Figure S1). Color-coded symbols are shown in the legends. 

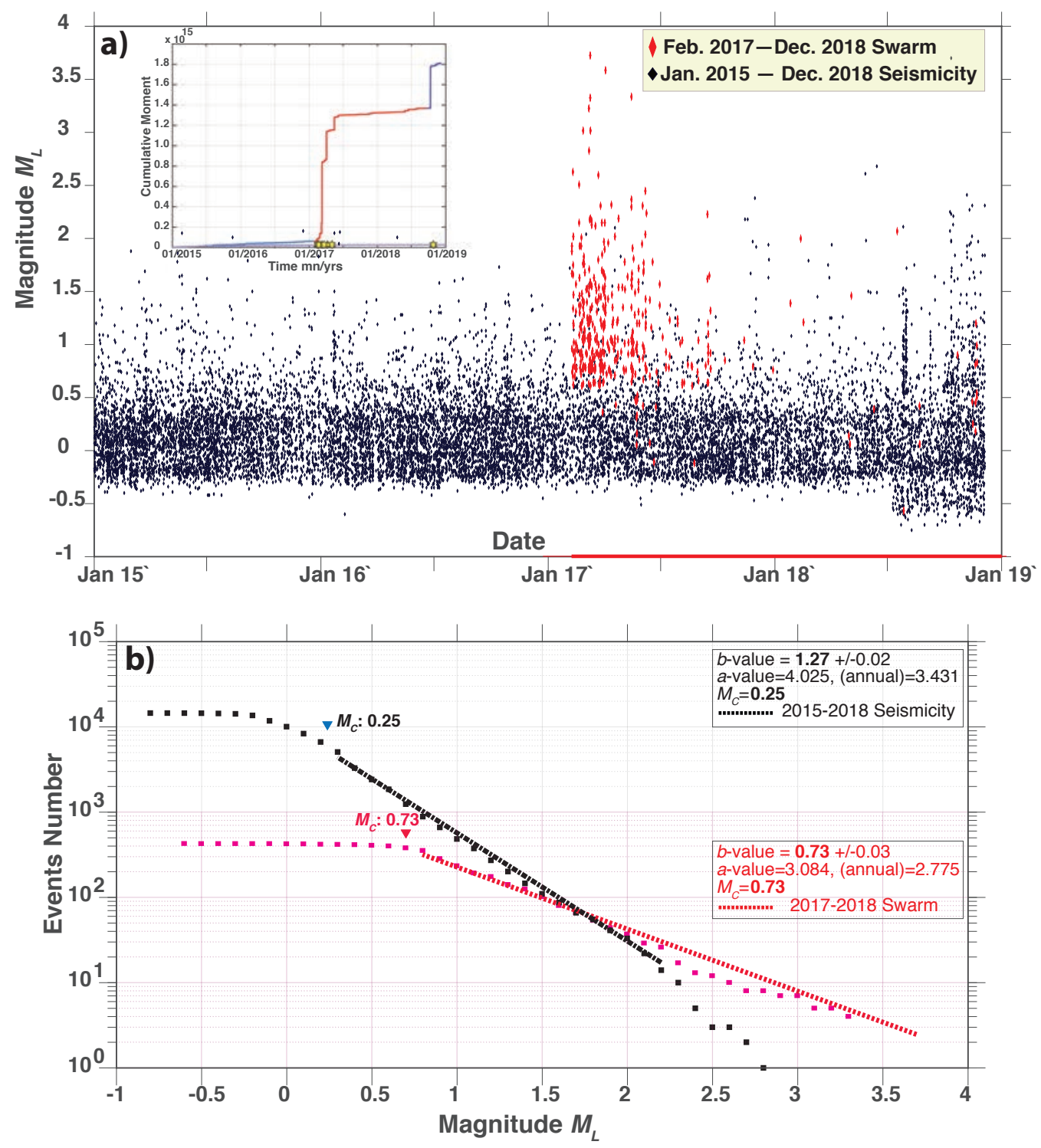

Figure 2: A) Seismicity data of $\sim 15 \mathrm{k}$ events recorded in the region of interest, where the red symbols represent the 2017 swarm, while the black dots show the background seismicity of Jan. 2015 to Dec. 2018. The inset represents a cumulative seismic moment release during the 2017 and 2018 swarms. B) Magnitude-frequency distributions (MFD) of all events in (A). The black symbols denote the background seismicity for the entire region of Harrat Lunayyir, while red color represents the 2017 swarm in the northern Lunayyir region. The squares denote number of earthquakes within each magnitude range. The dashed lines show the FMD fitted to the observed data. The inverted triangles (at $M_{C}=0.25$ and $M_{C}=0.73$, respectively) indicate the magnitude of completeness. 


\section{Event occurrence time (colors) with Magnitude (circle size)}

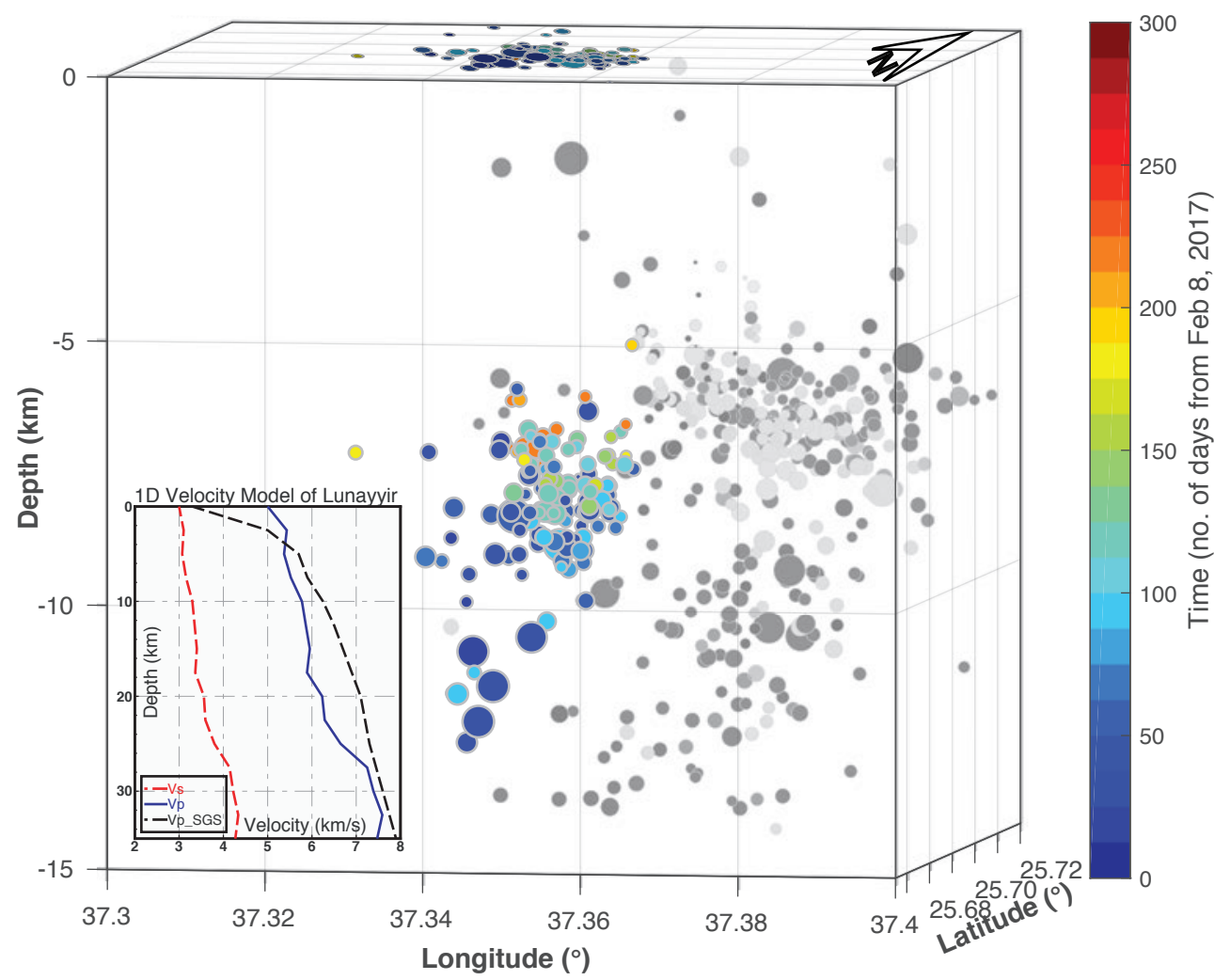

Figure 3: 3D representation showing both the double-difference relative relocation (using differential traveltimes of both P- and S-phases) and the standard network techniques (grey scale circles). The circle size represents the magnitude. The cluster of circles on the zero-level depth shows the surface projections of this swarm events. The lower inset is the velocity models used by SGS (dashed black) and this study (colored [Tang et al. 2016]). 

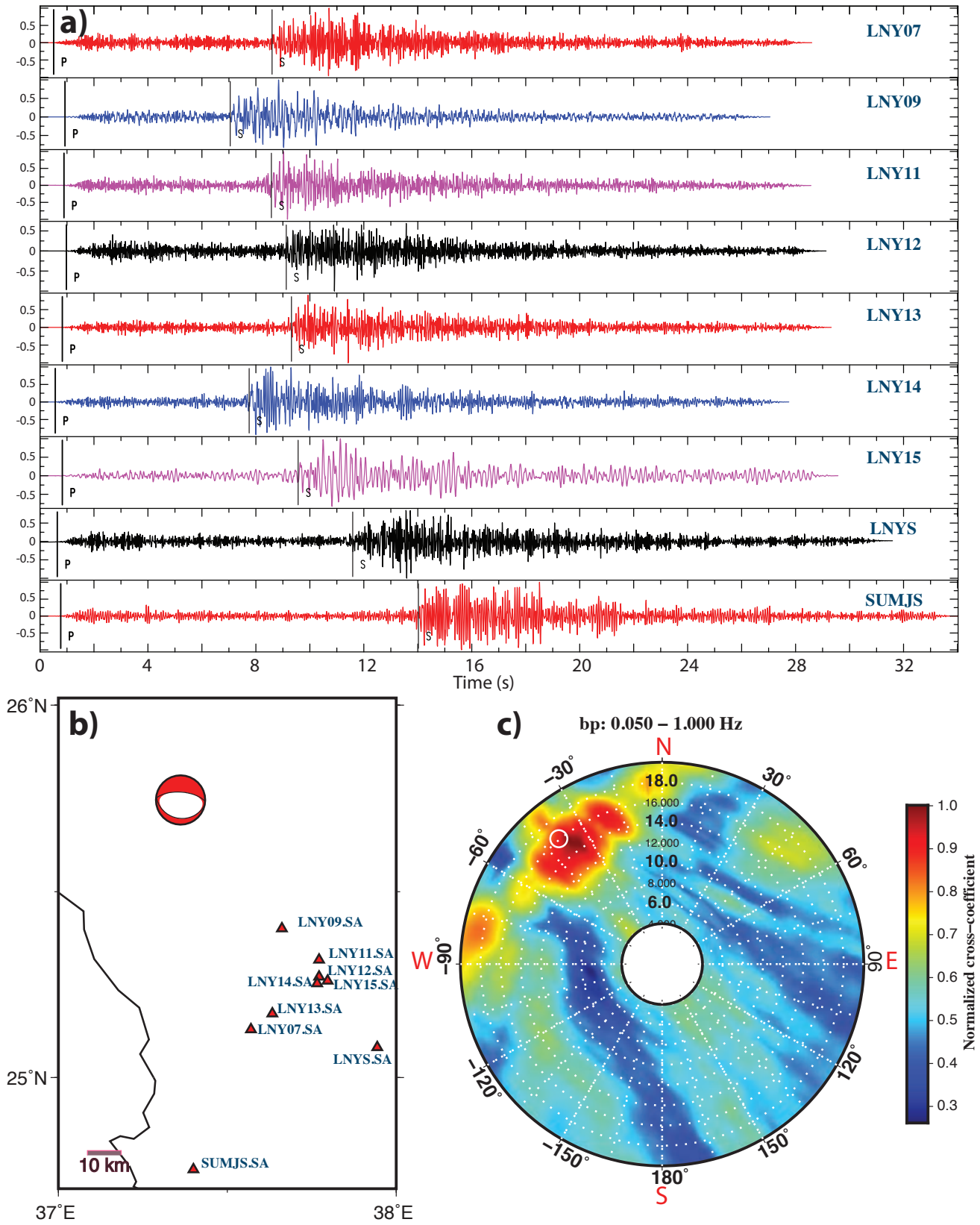

Figure 4: a) Vertical component signals (the largest event of 2017) for selected stations, which covers the southeastern sector (with respect to the 2017 swarm location), with stations average interspace of $6.11 \mathrm{~km}$. b) Location map of the stations with the above (a) records. The beachball marks the location for one single event as a reference point for the fracture zone. The reference point between stations used to evaluate the inter-station spacing is at $0.66^{\circ}$ from the selected event (the geographic mid-point between the event and all stations). c) The fk-analysis diagram shows a $\mathrm{P}$-wave arriving with an average slowness of $15.65 \mathrm{~s}^{\circ}$ along 4 back azimuth of $324^{\circ}$. The slowness from 4 to $20 \mathrm{~s}^{\circ}$ is displayed on the radial axis; the back azimuth is shown clockwise from $0^{\circ}$ to $360^{\circ}$. The observed slowness and back azimuth of the maximum power is marked with the darkest red color. Theoretical mean slowness and back azimuth values are marked by a white circle for the $\mathrm{P}$ arrival of event on March 10, 2017 (see supplementary Table S2). 


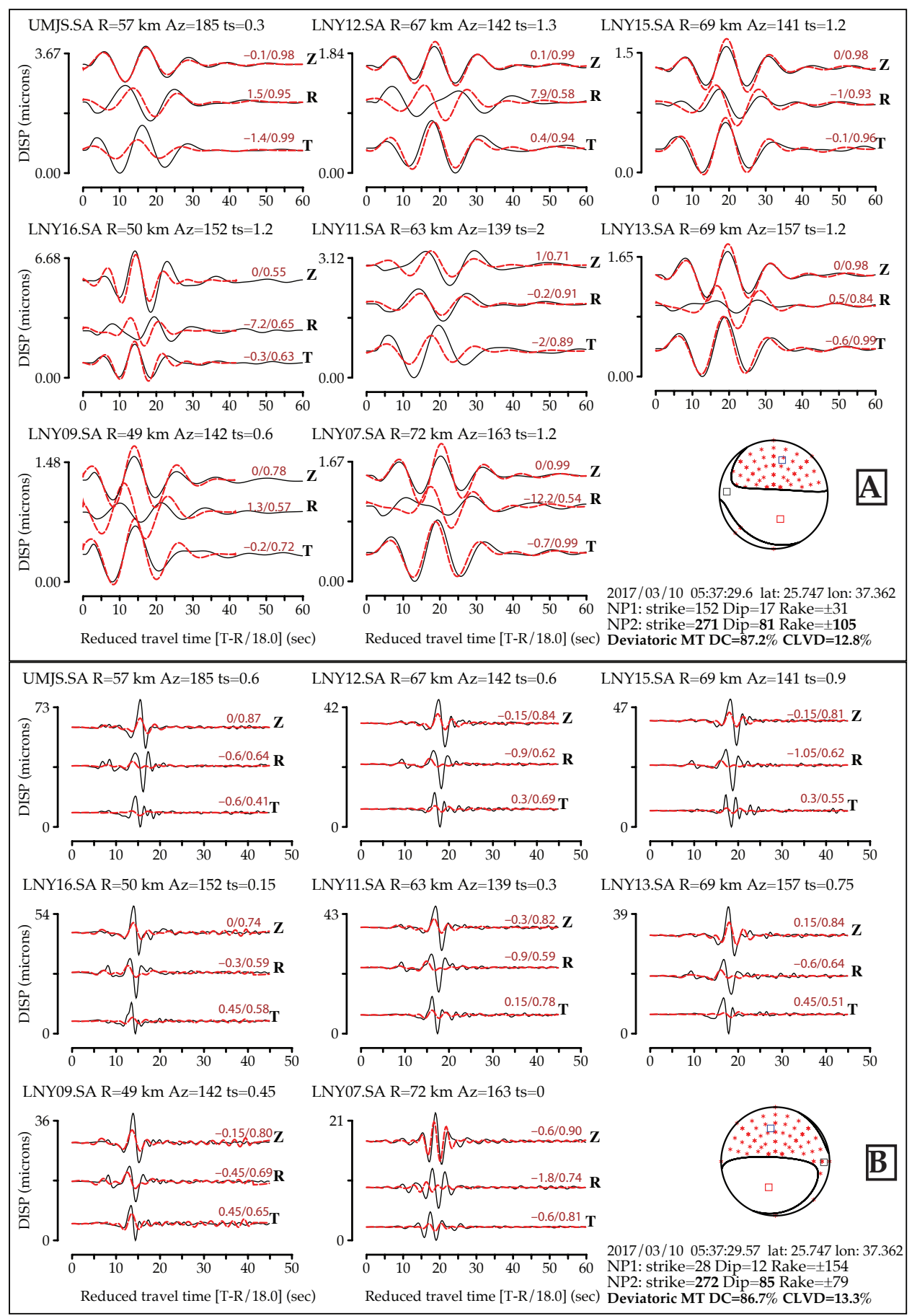

Figure 5: Moment tensor solution for the largest event (March 10th, 2017 at 17:37:10), with waveform fits (red synthetics; black observed displacement). We used a bandpass filter of A) $5-25 \mathrm{~s}(0.04 \mathrm{~Hz}-0.2 \mathrm{~Hz})$ for the low-frequency data, and B) $1-10 \mathrm{~s}(0.1 \mathrm{~Hz}-1 \mathrm{~Hz})$ for the high-frequency data. The values to the right of each seismogram component show the variance reduction (\%) and time-shift(sec). The $\mathrm{x}$-axis represertits reduced travel-time which includes a reduction velocity. 

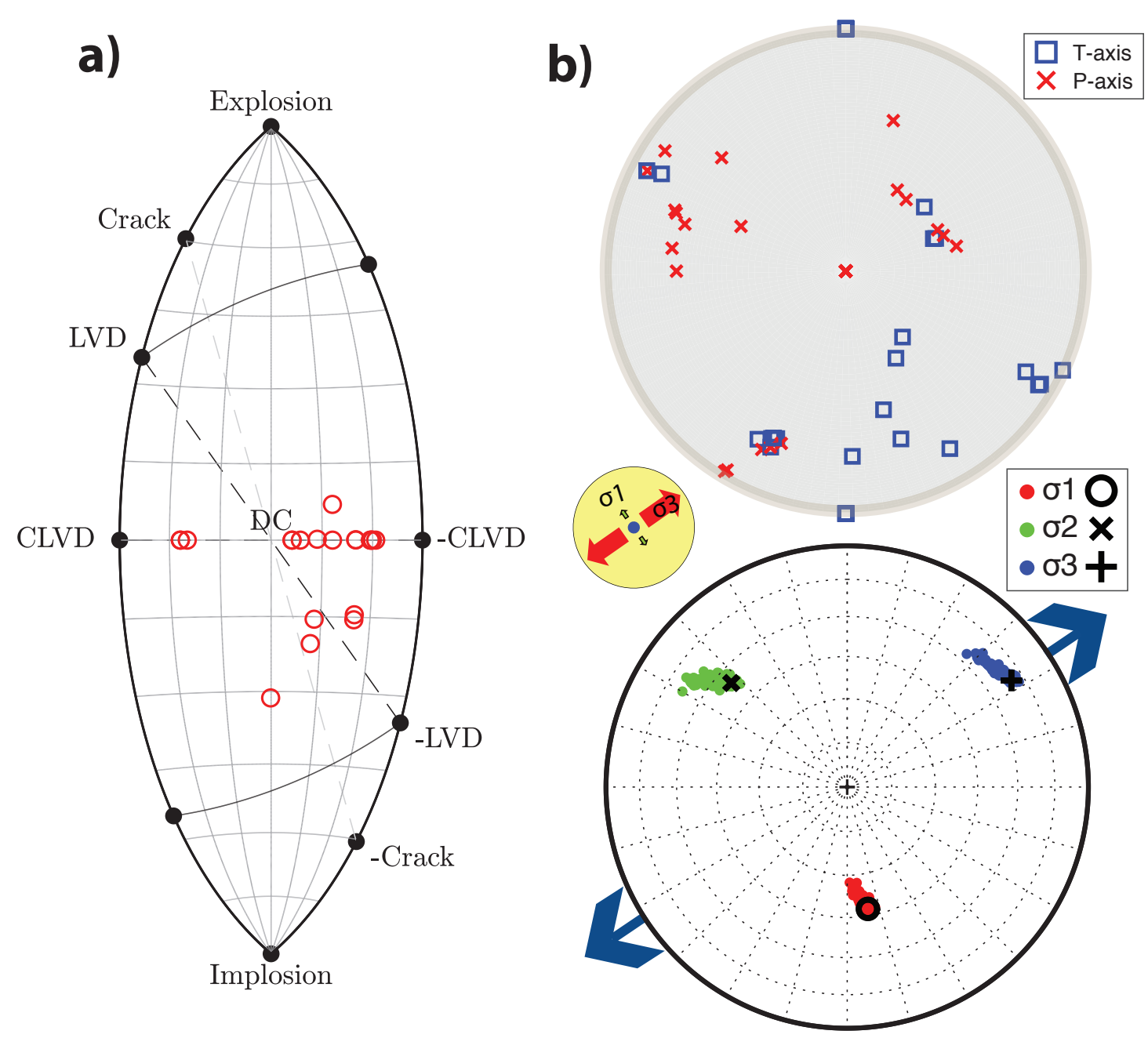

Figure 6: Full moment tensor datasets plotted on the fundamental lune representation of source types. Stress inversion results from focal mechanism solutions of events $\geq M_{L}$ 2.8. The yellow circular diagram shows the horizontal stress axes $\left(\sigma_{3} S h_{\max }\right.$ and $\left.\sigma_{1} S h_{\text {min }}\right)$. 

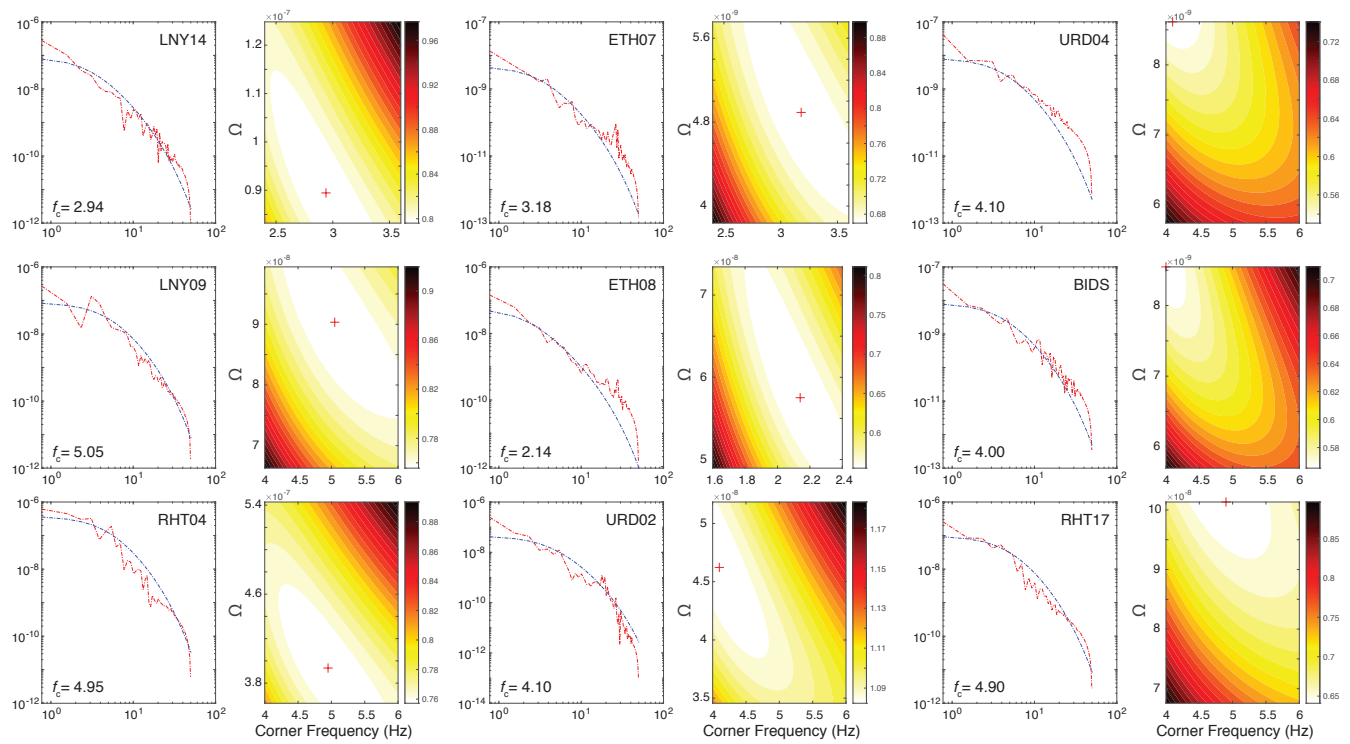

Figure 7: Fourier spectra of the $M_{L} 3.73$ event of March 2017 recorded at different stations (SH-component) that were used for calculation of earthquake source parameters. Corner frequencies $f_{c}$ values are shown in the plots. 

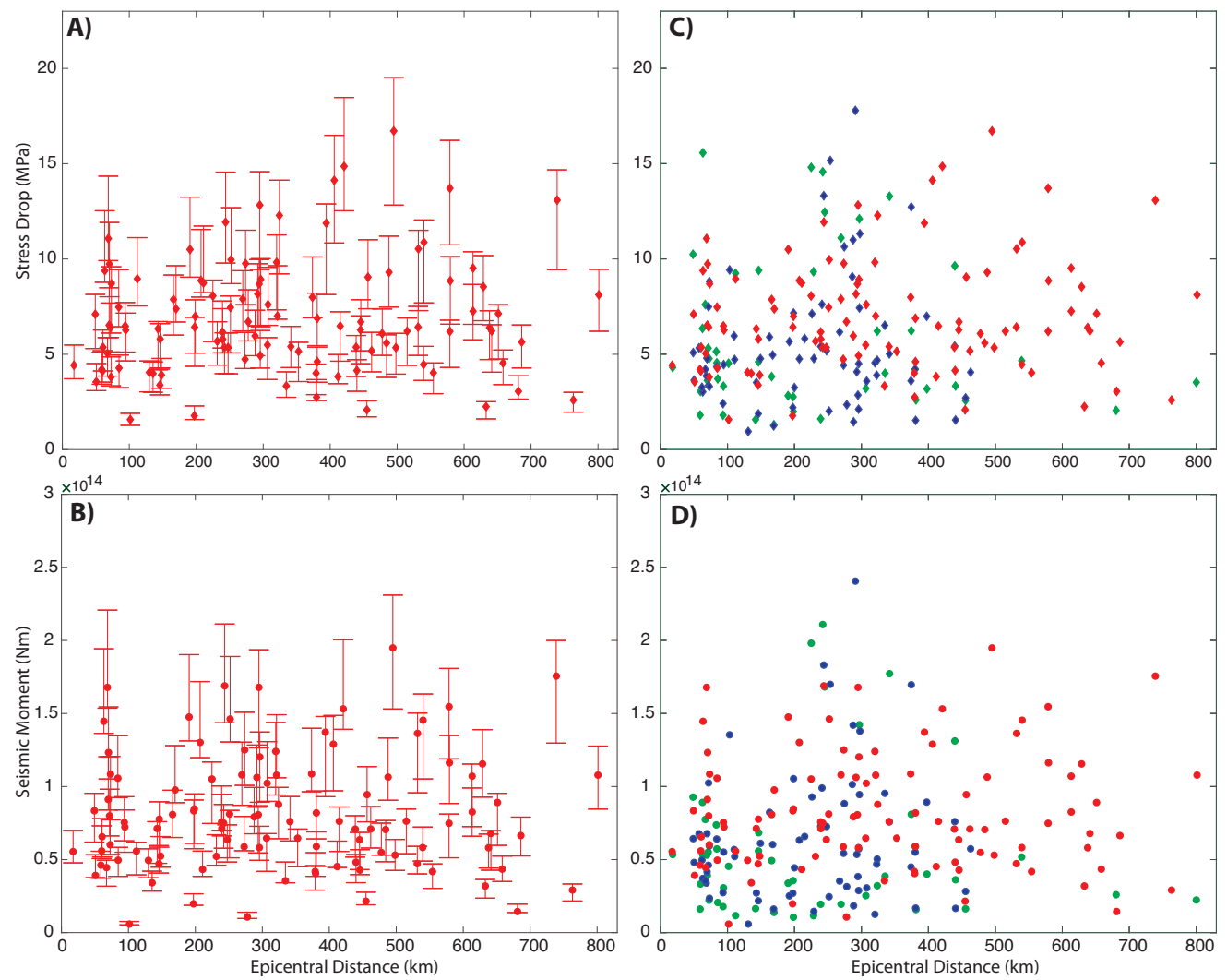

Figure 8: A) Stress drop and B) seismic moment vs epicentral distances calculated for the second largest event of April 3rd, $2017\left(M_{L} 3.59\right)$. The uncertainty estimates are data-driven using both $\mathrm{P}$ - and S-wave spectra as the limits of the mean values as shown. C) Stress drop and D) seismic moment vs epicentral distances calculated for the three largest events with $M_{L} 3.73$ (blue), 3.59 (red), 3.34 (green). 


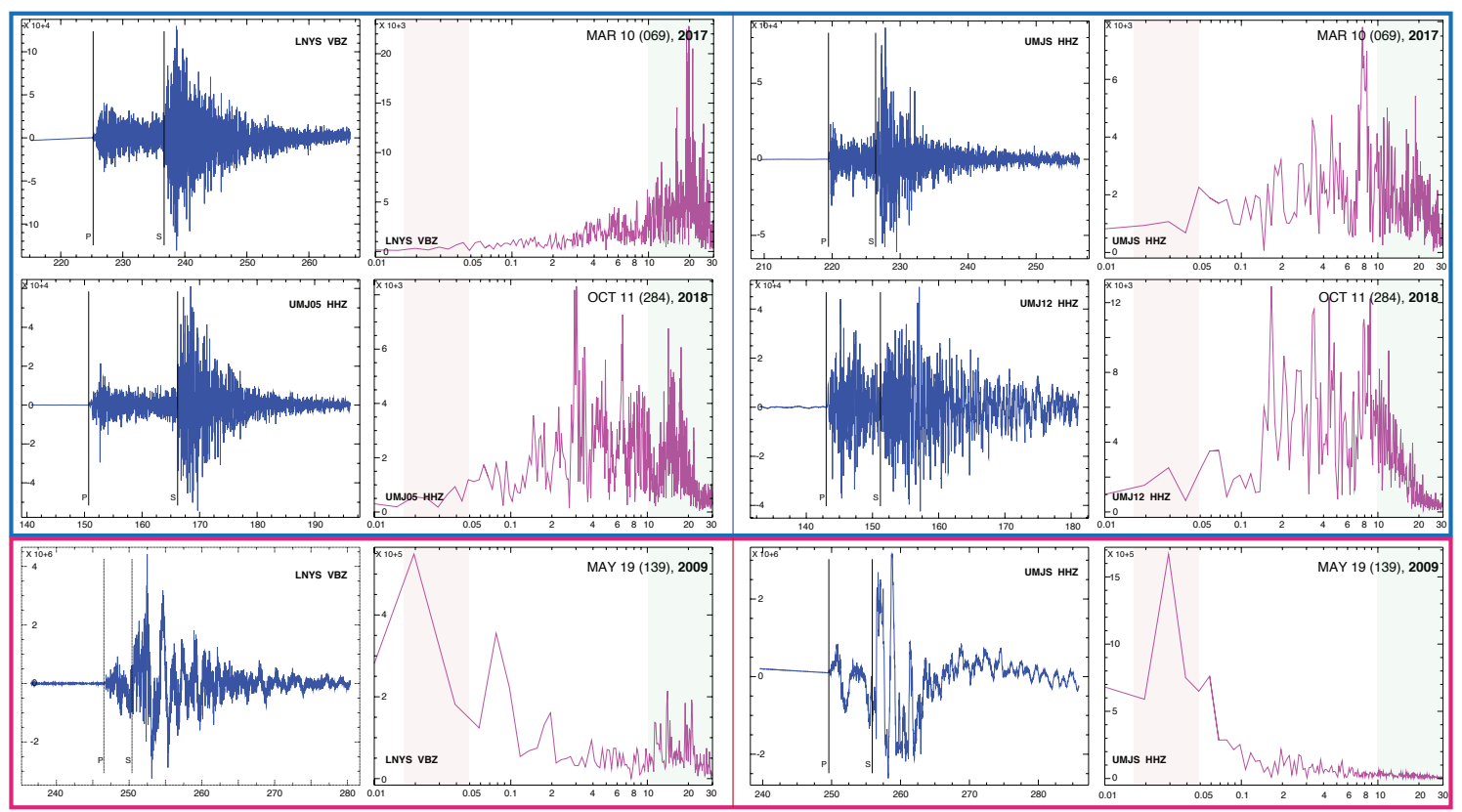

Figure 9: Comparison between frequency spectra for the tectonic event of March 10, 2017 (upper pane1) and the magmatic event of May 19, 2009 (lower panel). The event of October 11, 2018 (lower panel) which took place at the southwestern edge of Harrat Lunayyir might indicate a hybrid nature. Waveforms and corresponding frequency spectra show differences between the three cases. The low- and high-frequency bands are defined as 0.015$0.045 \mathrm{~Hz}$ and 10-30 Hz, respectively. 


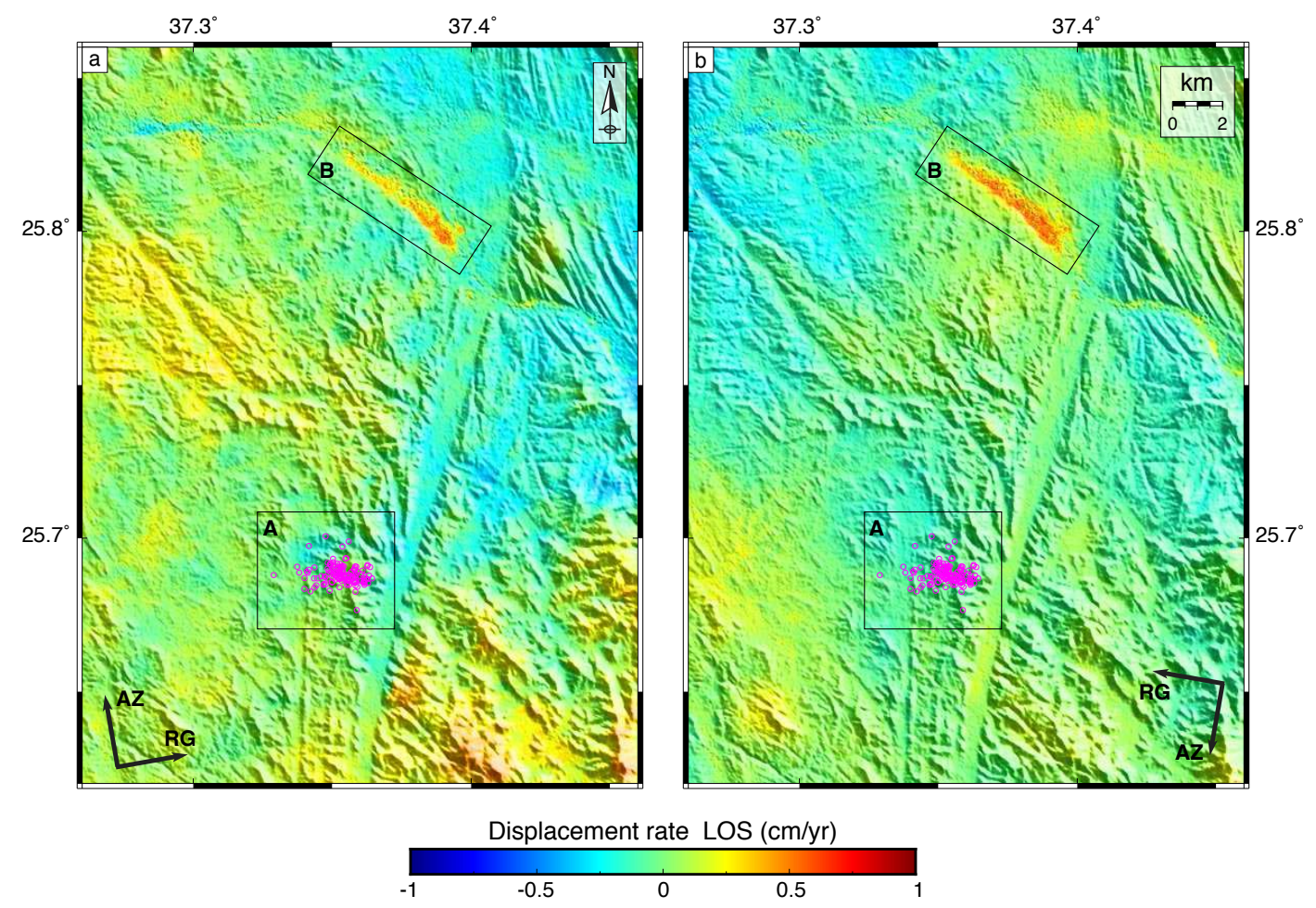

Figure 10: InSAR deformation rate maps in LOS obtained with Sentinel-1 images in ascending (a) and descending (b) orbits. Zone A is a $5 \mathrm{x} 4 \mathrm{~km}^{2}$ area where the seismic swarm occurred. Here, no evident signal associated to ground deformation is observed. Zone B is a $\sim 6 \mathrm{~km}$ North-West trending valley that corresponds to a dry riverbed. In both maps the area moves toward the satellite experiences uplift of $\sim 1.2 \mathrm{~cm} / \mathrm{yr}$, likely related to water level changes in a shallow aquifer. 